\title{
Efficacy of interpositional arthroplasty with temporalis myofascia flap in treatment of TMJ ankylosis
}

\begin{abstract}
Aims and objective: The present study was done to evaluate the efficacy of interpositional arthroplasty with temporalis muscle and fascia (myofascia) flap in preventing the reankylosis, to evaluate the growth of mandible, and to assess Al-Kayat and Bramley's incision for its versatility in allowing muscle transfer and excellent exposure of the joint.

Materials and Methods: Fifteen patients with ankylosis were treated with interpositional arthroplasty with temporalis myofascia flap. Maximum Interincisal Opening (MIO) was measured at different periods, i.e. preoperative, intraoperative, immediate post operative, 1 month post-operative, 6 month post-operative, 1 year post-operative. Pain was measured using Visual analogue scales in closed mouth position (spontaneously) \& on mouth opening. Six cephalometric points were taken for evaluating the mandibular growth

Results: A statistically significant difference of $30.73 \mathrm{~mm}(\mathrm{p}<0.001)$ was obtained between pre-operative and post-operative interincisal opening after a period of one year follow up. The pain score at different periods of time revealed that the pain incidence significantly reduced to almost zero post-operatively ( $\mathrm{p}<0.5$ for closed mouth, $\mathrm{p}<0.01$ for open mouth).
\end{abstract}

Conclusion: The temporalis myofascia flap is an efficient interpositional material that acts as a barrier and prevents the chances of reankylosis to a greater extent.

Keywords: interpositional arthroplasty, temporomandibular joint, temporalis myofascia flap
Volume I Issue 5 - 2014

\begin{abstract}
Amrit Pal Singh, Ajaz Ahmad Shah, Irshad Ahmad

Department of Oral \& Maxillofacial Surgery, Government Dental College, India
\end{abstract}

Correspondence: Amrit Pal Singh, Government Dental College, Jammu, India, Email drkarankahlon@gmail.com

Received: October 10, 2014 | Published: October 27, 2014
Abbreviations: MIO, Maximum Interincisal Opening; SMV, Submentovertex

\section{Introduction}

Ankylosis of temporomandibular joint is an affliction which occasions much misery for the unfortunate victim, interfering with the mastication and digestion of food, denying the body the benefits of a balanced diet, and preventing participation in the pleasures traditionally associated with the culinary arts. If the condition develops in childhood, facial deformity brings psychological stress which adds to the physical handicap, thus disturbing family life and creating emotional disturbance". 1,2

Trauma is well proven to be the predominant cause of temporomandibular joint ankylosis. The other causes that could lead to TMJ ankylosis are local or systemic infections (like otitis media in the childhood), tumors, systemic diseases like ankylosing spondylitis, rheumatoid arthritis and psoriasis, and a complication of previous TMJ surgery. ${ }^{3}$

TMJ ankylosis may be unilateral or bilateral. According to the type of tissue involved it is classified as bony or fibrous ankylosis. Sawhney offered a lucid classification of ankylosis which is helpful in selecting an appropriate, corrective operation. ${ }^{4}$

Whatsoever may be the type, early surgical correction of the deformity soon followed by jaw mobility exercises should be encouraged in order to get good results out of surgery and also prevent future reankylosis. ${ }^{2}$
Surgical intervention by resection of the ankylotic mass through gap arthroplasty alone resulted in reankylosis. Attempts have been made to prevent such reankylosis with interpositional arthroplasty. Numerous materials have been interposed between the resected bone surface and articular fossa at the base of the skull. Alloplastic materials such as silicone, silastic, proplast, Teflon, rubber prosthesis, metals, methyl methacrylate; and autogenous material such as full thickness skin, dermis, fascia, auricular cartilage, fat, Lyodura, costochondral graft, metatarsals, metacarpophalangeal joint transfer, sternoclavicular joint transfer and temporalis muscle and fascia have been used. .,6 $^{5}$

Non-biologic materials like acrylic though cost effective and less time consuming present the risk of foreign body reactions, hypersensitivity and slippage. Silicone also has a tendency to slip from the implanted position. Lyodura is abandoned due to the possible transmission of Creutzfeldt-Jakob disease. ${ }^{7,8}$ Autogenous materials present problem of a second surgical site. Temporalis Myofascial flap due to its proximity to the joint and high vascular supply has been considered as one of the best interpositioning materials used. ${ }^{9}$

The aim of this study was to carry out retrospective and prospective assessment to evaluate the efficacy of interpositional arthoplasty with temporalis muscle and fascia (myofascia) flap in preventing the reankylosis, to evaluate the growth of mandible, and to assess Al-Kayat and Bramley's ${ }^{10}$ incision for its versatility in allowing muscle transfer and excellent exposure of the joint. 


\section{Materials and methods}

This retrospective and prospective study was conducted in the Department of Oral and Maxillofacial Surgery, Govt. Dental College, Srinagar. Fifteen patients with TMJ ankylosis were included in the study, of which 7 were males and 8 were females with a mean age of 14.2 years (ranging from 5 years to 26 years).

Patients who reported to the Department with a chief complaint of inability to open the mouth were included in the study on the basis of clinical examination and only those patients who presented with a restricted mouth opening secondary to ankylosis were selected for the study (Figure 1).

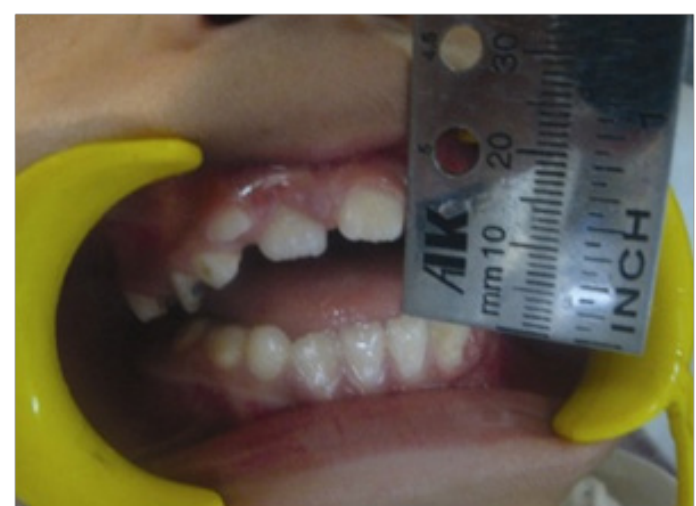

Figure I Showing restricted mouth opening.

During this two and a half years period of study (June 2007 to Nov 2010) 15 patients with ankylosis were treated with interpositional arthroplasty with temporalis myofascia flap (Figure 2).

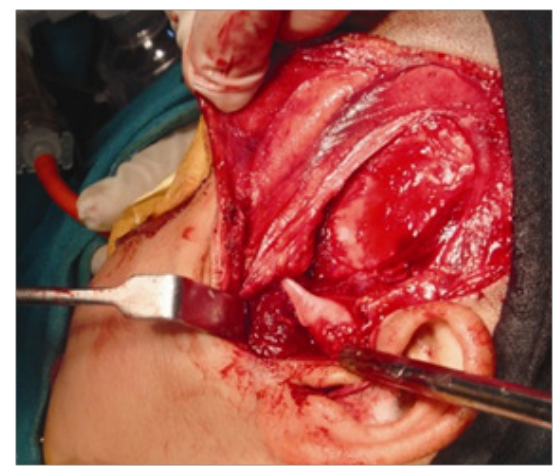

Figure 2 Management of ankylosis with temporalis myofascia flap.

The information that was collected mainly focused on the age at which patient reported to the department and age of occurrence of the condition. A diagnosis of unilateral / bilateral TMJ ankylosis was mainly obtained with the help of extraoral and intraoral examinations and OPG. Rarely PA view and special views like submentovertex (SMV) were used to assess coronoid. CT scan (axial and coronal views) was done in all patients in order to know the medial extent of the ankylotic mass. 3D-CT was used for one patient. Lateral cephalograms were also taken to assess the mandibular growth.

The parameter taken was Maximum Interincisal Opening (MIO) taken at different periods, i.e. preoperative, intraoperative, immediate post operative, 1 month post-operative, 6 month post-operative, 1 year post-operative. Pain was measured on the basis of grades using Visual analogue scales as No pain (0), mild pain (1) VAS 1-4, moderate pain (2) VAS 5-7, and severe pain (3) VAS 8-10. Preoperative pain was measured in closed mouth position (spontaneously) \& on mouth opening, followed by 6 months and 1 year later both in closed mouth position \& on mouth opening.

Six cephalometric points were taken for evaluating the mandibular growth. Articulare (Ar) to Gonion (Go) for vertical growth of ramus. Gonion (Go) to Pogonion (Pg) for anterioposterior growth of mandible. Point B to Menton (Me) for vertical growth at symphysis region.

Informed consent for difficult intubation and emergency tracheostomy was obtained from all patients/guardians in case of minors. Tracheostomy was done for all patients except one in whom blind nasal intubation was successful.

The operative protocol consisted of

a. Resection of ankylotic mass through an extended preauricular approach as described by Al-Kayat and P. Bramley (Figure 3).

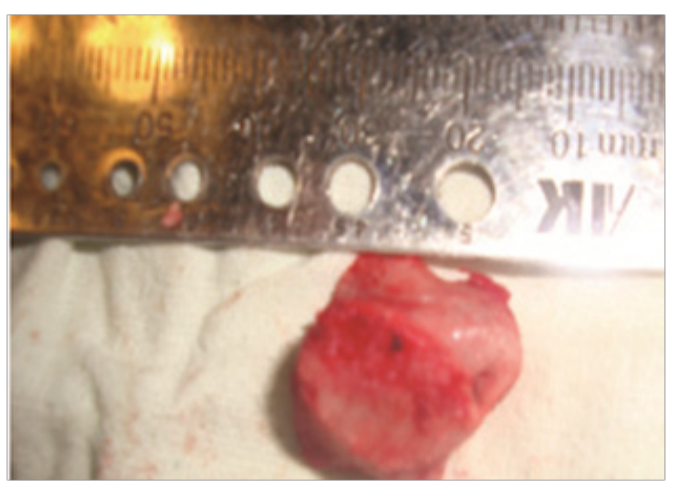

Figure 3 Resection of ankylotic mass by Al-Kayat \& P Bramley. ${ }^{10}$

b. Intraoral ipsilateral coronoidectomy. Removal of the ankylotic mass was performed to create a minimum gap of $1-1.5 \mathrm{cms}$, until the maximum mouth opening ranging from $30-35 \mathrm{~mm}$ was achieved on the table

c. Contralateral coronoidectomy when required

d. Harvesting and rotation of the temporalis myofascial flap beneath the zygomatic arch into the glenoid fossa

e. Physiotherapy was continued for several months if deemed necessary. Regular checkups were carried out for one year. The data collected was tabulated and subjected to appropriate statistical analytical tests.

\section{Results}

The study evaluated 15 patients with ankylosis of the temporomandibular joint. Seven (46.66\%) patients had only one TMJ involved and $8(53.33 \%)$ patients showed bilateral ankylosis, making a total of 23 joints. Maximum patients (13) reported in first two decades of life. 4 patients reported in the age groups of 1-10 years (26.66\%), 9 patients reported in the age group of $11-20$ years $(60 \%)$ and 2 in the age group of 21 to 30 years. Out of the total, 7 (46.66\%) were males and $8(53.33 \%)$ were females. All the patients showed etiologic factors with trauma responsible for all the cases of TMJ Ankylosis.

Mean difference of $30.73 \mathrm{~mm}(\mathrm{p}<0.001)$ between pre-operative and post-operative interincisal opening after a period of one year follow up. The results were statistically significant using paired t-test (Table 1). 
Chart 1 shows pain score at different periods of time. In the closed mouth position the spontaneous pain scores were 0.9 preoperatively, 0.3 and 0.06 at six months and 1 year respectively. When the

Table I Maximum interincisal opening (in $\mathrm{mm}$ ) patient tends to open his mouth, the score was 2.1, 0.6 and 0.2 for preoperative, 6 months and 1 year respectively. This shows that pain incidence has significantly reduced to almost zero post-operatively ( $p<0.5$ for closed mouth, $\mathrm{p}<0.01$ for open mouth).

\begin{tabular}{llll}
\hline $\begin{array}{l}\text { Time of } \\
\text { Assessment }\end{array}$ & Mean \pm SD & $\begin{array}{l}\text { Difference from Pre- } \\
\text { Operative }\end{array}$ & p-value \\
\hline Pre-Operative & $4.2 \pm 2.9$ & - & - \\
Intra-Operative & $39.0 \pm 3.0$ & 34.800 & $<.001$ \\
$\begin{array}{l}\text { Immediate } \\
\text { Post-operative }\end{array}$ & $26.06 \pm 3.3$ & 21.867 & $<.001$ \\
I Month & $33.33 \pm 2.5$ & 29.133 & $<.001$ \\
6 Months & $35.06 \pm 2.2$ & 30.867 & $<.001$ \\
I Year & $34.93 \pm 2.2$ & 30.733 & $<.001$ \\
\hline
\end{tabular}

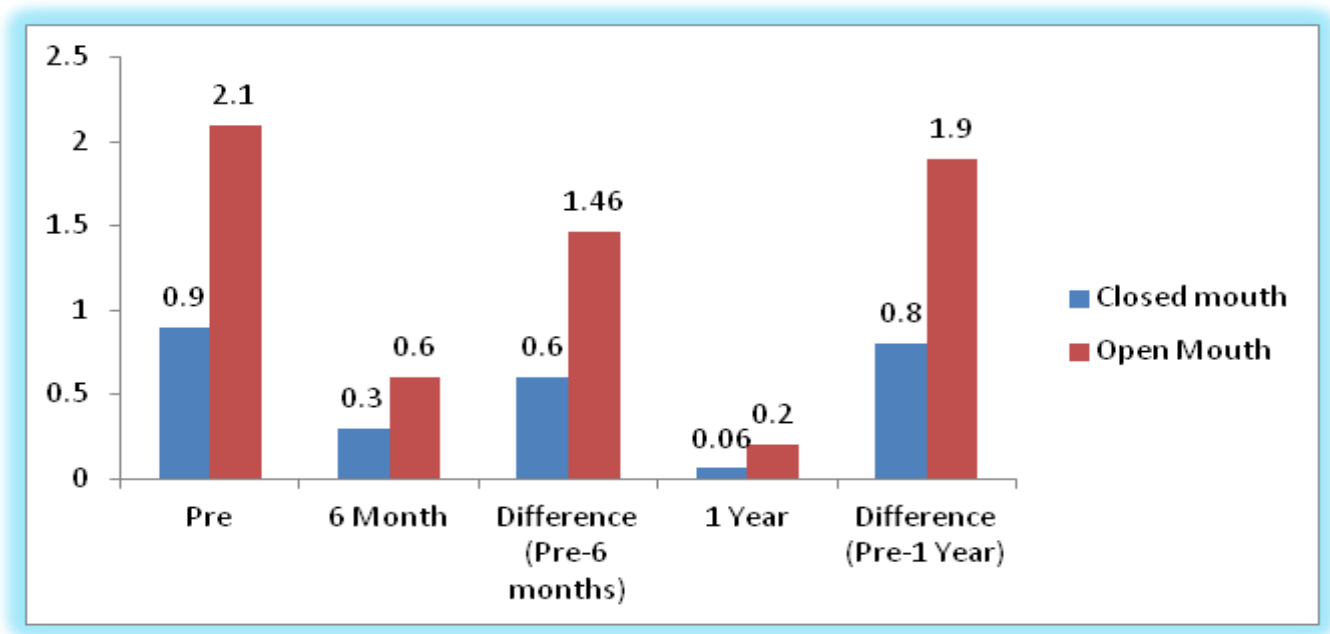

Graph I Pain score (vas) at different periods of time.

Paired t- test; $\mathrm{P}<.05, \mathrm{P}<.0$ I Significant changes

Table 2 shows the mean cephalometric measurements comparing the growth changes of mandible in anterioposterior and vertical directions. Mean growth change in vertical ramus height from Ar-Go in 6 months and 1 year was $0.4 \pm 0.5 \mathrm{~mm}$ and $0.93 \pm 0.8 \mathrm{~mm}$ respectively $(p<0.01$, significant). Similarly, in anterioposterior direction from
Go-Pg it was $0.26 \pm 0.4 \mathrm{~mm}$ in six months and $1.00 \pm 0.8 \mathrm{~mm}$ in 1 year $(\mathrm{p}<0.01$, Significant). Also at symphyseal region between Point $B$ and Me there is significant change of $0.06 \pm 0.2 \mathrm{~mm}$ in six months and about $0.53 \pm 0.5 \mathrm{~mm}$ in 1 year $(\mathrm{p} \leq 0.33, \mathrm{p}<0.01)$.

Table 2 Cephalometric measurements for mandibular growth (in $\mathrm{mm}$ )

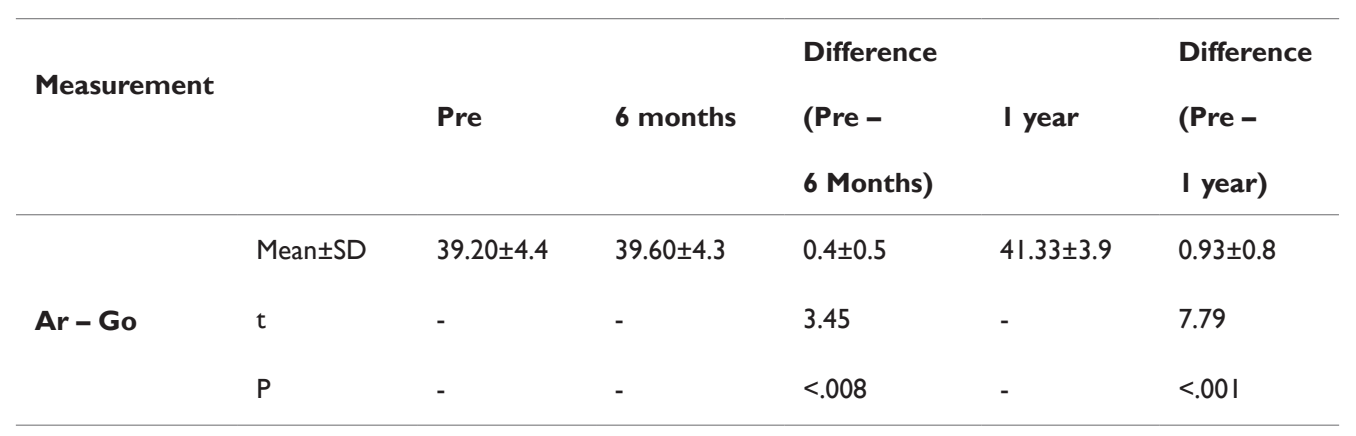


Table Continued...

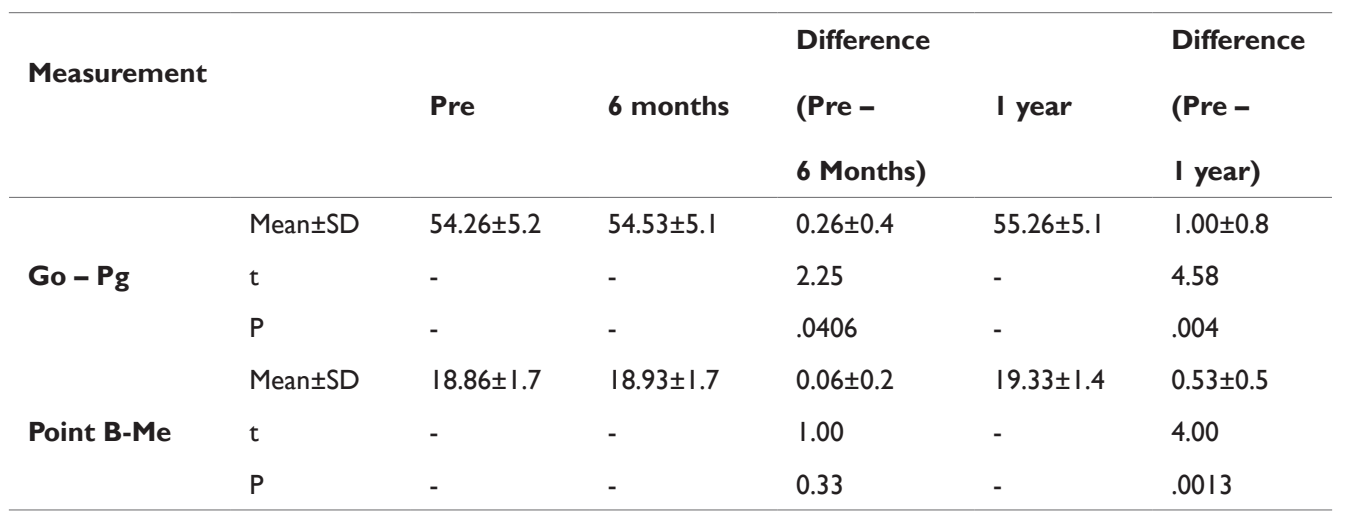

\section{Discussion}

Ankylosis of the temporomandibular joint makes mastication impossible, deteriorates oral hygiene, and impairs speech. It may also give rise to psychological problems. ${ }^{11}$

Ankylosis might occur at any age. The reported age distribution ranges from 2 to 63 years, the highest incidence being in the 1019 year age group. ${ }^{12}$ In present study 15 patients, about 13 patients reported the onset of ankylosis before 10 years of age; two patients had it at the age of 10 years and 12 years respectively. Thus, about $86.66 \%$ of the patients had the onset of ankylosis before the age of 10 .

The cases selected were only of intra articular ankylosis for this study and all patients had bony ankylosis. There is unanimous agreement that surgery is the treatment of choice for ankylosis $f$ the temporomandibular joint. The principal surgical procedures are gap arthroplasty, interpositional arthroplasty and joint reconstruction with autogenous or alloplastic materials.

The technique of gap arthroplasty has been supported by various authors like Rajgopal et al. ${ }^{13}$ \& Roychoudhary et al. ${ }^{14}$ They state that excision of an adequate amount of bone is imperative and if done in that way, interposition of any material becomes unnecessary. Although advantages of gap arthroplasty are its simplicity and short operative time, clinical experience and the literature on ankylosis suggest that in spite of creating a wide gap, the recurrence rate is quite high. ${ }^{15}$

Hence the concept of interpositional arthroplasty was born, in which an interpositional medium is placed between the severed ends of the bone to act as an obstacle to reunion. A variety of interpositional materials have been used including alloplastic and autogenous materials.

Alloplastic materials have not been very successful in preventing reankylosis. This is because of the fact that although the bone surfaces are prevented from contacting each other, bone can form on both sides and eventually bridge the gap. There is a possibility of rejection of the foreign material also. The use of alloplastic materials also may result in severe degenerative changes and possible systemic release of particles. ${ }^{16,17}$ To avoid these complications, a variety of autogenous materials are advocated.

We have used Al-Kayat and Bramley ${ }^{10}$ incision which gives wide exposure with adequate visibility, prevents damage to the nerves and at the same time allows raising a pedicled flap of temporalis myofascia flap. Similar incision has been used by Chidzonga, ${ }^{18}$ Mehrotra et al. ${ }^{19}$ \& Danda et al. ${ }^{20}$ in TMJ ankylosis patients in their respective studies.
Su-Gwan determined the efficacy of interpositional arthroplasty with temporalis myofascia flap in the treatment of unilateral temporomandibular joint ankylosis in adults. Patients had a mean preoperative maximal interincisal opening of $15 \mathrm{~mm}$. During the last follow up observation after surgery the patients had a mean maximal interincisal opening of $36.1 \mathrm{~mm}$. Pre operatively all patients had some degree of pain in the joint involved which significantly decreased after the operation. ${ }^{2}$

Brusati et al used the temporalis muscle flap to treat the severely damaged TMJ structural components. Using this surgical technique $13 \mathrm{TMJ}$ yielded positive functional results without any complication. ${ }^{21}$ In the present study, the temporalis myofascia flap was evaluated to be efficient in preventing the reankylosis. Preoperatively the mean interincisal opening was $4.2 \mathrm{~mm}$ and post-operatively after a period of 1 year follow-up it remained as $34.93 \mathrm{~mm}(\mathrm{P}<0.001)$. Only in one patient the mouth opening was reduced to less than $30 \mathrm{~mm}$. This is because the patient did not follow the post operative regimen of mouth exercises and physiotherapy which play an important role in preventing the post-operative adhesions. In this study, preoperatively almost all patients had some degree of pain in joint spontaneously or on opening the mouth. But after the interpositional arthroplasty with temporalis myofascia flap, the pain incidence was significantly reduced. This is in conformity with the findings of Su-Gwan ${ }^{2}$ who reported a general decrease in pain ratings after the operation.

Sorensen and Laskin ${ }^{22}$ explained the mandibular growth after ankylosis treatment on the basis of functional matrix theory. Restoration of normal function is therefore mandatory for restoring normal growth. In this data, according to cephalometric measurements, mean growth change in vertical ramus height from Ar-Go in 6 months and 1 year was $0.4 \mathrm{~mm}$ and $0.9 \mathrm{~mm}$ respectively ( $<<0.01$, significant). Similarly the body growth in anterioposterior direction from Go-Pg was $0.2 \mathrm{~mm}$ in six months and $1.0 \mathrm{~mm}$ in 1 year ( $<<0.01$, significant). Similarly at symphyseal region between Point B and Me there is a change of $0.2 \mathrm{~mm}$ in six months and about $0.5 \mathrm{~mm}$ in 1 year. Thus after the release of ankylosis, the mandibular growth continued corresponding to the normal population, but the growth deficit already occurred, could not be made up. There was no accelerated growth spurt as such.

\section{Conclusion}

The temporalis myofascia flap is an efficient interpositional material. It is a biologic, autogenous tissue, so there is no question of any rejection. It is a pedicled flap, so it maintains its viability. It can be procured by the same incision used for exposure of the joint. It is 
easily mobilized and made to cover the complete area of the glenoid fossa. Thus it acts as a barrier and prevents the chances of reankylosis to a greater extent. Also the mandibular growth continues as normal after the temporalis myofascia interposition.

\section{Funding details}

None.

\section{Acknowledgments}

None.

\section{Conflicts of interest}

The authors declare that there is no conflict of interest.

\section{References}

1. Ugboko V, Amole AOD, Olasoji HO, et al. Temporomandibular joint ankylosis: a multicenter Nigerian study. Online J Dent Oral Med. 2002;4:1-15.

2. Su-Gwan K. Treatment of temporomandibular joint ankylosis with temporalis muscle and facial flap. Int J Oral Maxillofac Surg. 2001;30:189-193.

3. El-Sayed KM. Temporomandibular joint reconstruction with costochondral graft using modified approach. Int J Oral Maxillofac Surg. 2008;37:897-902.

4. Sawhney CP. Bony ankylosis of the temporomandibular joint: Follow-up of 70 patients treated with arthroplasty and acrylic spacer interposition. Plast Reconstr Surg. 1986;77(1):29-38.

5. Zhu SS, Hu J, Li J, et al. Free grafting of autogenous coronoid process for condylar reconstruction in patients with temporomandibular joint ankylosis. Oral Surg Oral Med Oral Pathol Oral Radiol Endod. 2008;106:662-667.

6. Medra AM. Follow up of mandibular costochondral grafts after release of ankylosis of the temporomandibular joints. Br J Oral Maxillofac Surg. 2005;4:118-122.

7. Mac Intosh RB. The use of autogenous tissue for temporomandibular joint reconstruction. J Oral Maxillofac Surg. 2000;58:63-69.

8. Balaji SM. Modified temporalis anchorage in craniomandibular reankylosis. Int J Oral Maxillofac Surg. 2003;32:480-485.

9. Ahmad Q, Siddiqui R, Khan A, et al. Interposition arthroplasty in TMJ ankylosis. Indian Journal of Otolaryngology and Head and Neck Surgery. 2004;26(1):5-8.
10. Al-Kayat A, Bramley P. Modified preauricular approach to the temporomandibular joint and malar arch. Br J Oral Maxillofac Surg. 1979;17:91-103.

11. Martins WD. Report of ankylosis of the temporomandibular joint: treatment with a temporalis muscle flap and augmentation genioplasty. $J$ Contemp Dent Pract. 2006;7(1):125-133.

12. Archer WH. Oral and Maxillofacial Surgery. Philadelphia: W.B. Saunders Company; 1975. 1527-1539 p.

13. Rajgopal A, Banerji PK, Batura V, et al. Temporomandibular ankylosis. A report of 15 cases. J Maxillofac Surg. 1983;11:37-41.

14. Roychoudhury A, Parkash H, Trikha A. Functional restoration by gap arthroplasty in temporomandibular joint ankylosis: A report of 50 cases. Oral Surg Oral Med Oral Pathol Oral Radiol Endod. 1999;87:166-169.

15. Matsuura H, Miyamoto $\mathrm{H}$, Ogi N, et al. The effect of gap arthroplasty on temporomandibular joint ankylosis; an experimental study. Int J Oral Maxillofac Surg. 2001;30:431-437.

16. Tuncel U, Ozgenel GY. Use of Human Amniotic Membrane as an Interpositional Material in Treatment of Temporomandibular Joint Ankylosis. J Oral Maxillofac Surg. 2011;69:e58-66.

17. Ozgenel GY, Filiz G. Combined application of human amniotic membrane wrapping and hyaluronic acid injection in epineurectomized rat sciatic nerve. J Reconstr Microsurg. 2004;20:153-157.

18. Chidzonga MM. Temporomandibular joint ankylosis review of thirty two cases. Br J Oral Maxillofac Surg. 1999;37:123-126.

19. Mehrotra D, Pradhan R, Mohammad S, et al. Random control trial of dermis-fat graft and interposition of temporalis fascia in the management of Temporomandibular joint ankylosis in children. $\mathrm{Br} J$ of Oral and Maxillofacial Surgery. 2008;46:521-526.

20. Danda AK, Ramkumar S, Chinnaswami R. Comparision of gap arthroplasty with and without a temporalis muscle flap for the treatment of ankylosis. J Oral Maxillofac Surg. 2009;67:1425-1431.

21. Brusati R, Raffaini M, Sesenna E, et al. The temporalis muscle flap in Temporo-Mandibular joint surgery. J Cranio Max Fac Surg. 1990;18:352358.

22. Sorensen DC, Laskin DM. Facial growth after condylectomy or osteotomy in the mandibular ramus. J Oral Surg. 1975;33:746. 